\title{
Sero-prevalence and associated factors of Helicobacterpylori infection among adult patients with dyspepsia attending the gastroenterology unit in a tertiary hospital in Mwanza, Tanzania.
}

\author{
Hyasinta Jaka ${ }^{1}$, Martha F. Mushi ${ }^{2}$, Mariam M Mirambo², Leonard Wilson², \\ Jeremiah Seni ${ }^{2}$, Majigo Mtebe ${ }^{3}$, Stephen E. Mshana ${ }^{2}$
}

1. Department of Internal medicine, Weill Bugando School of Medicine, P.O.Box 1464, Mwanza, Tanzania.

2. Department of Microbiology/Immunology, Weill Bugando School of Medicine, P.O.Box 1464, Mwanza, Tanzania.

3. Department of Microbiology and Immunology, Muhimbili university of Health and allied sciences P.O.Box 65001, Dar es Salaam.

\begin{abstract}
Background: Prevalence of H.pylori infection varies greatly between populations in different countries. This study was conducted to determine the magnitude of H.pylori among adult patients with dyspepsia attending the gastroenterology unit at Bugando medical centre.

Methods: A cross sectional study involving 202 dyspeptic patients was conducted between June and July 2014. A Standardized data collection tool was used to collect socio-demographic characteristics. H.pylori antibodies were detected using rapid immunochromatographic tests according to manufacturer's instructions.

Results: The median age of study population was 42 (IQR: 33-54). Females 105 (51.9\%) formed majority of the population studied. Of 202 participants; 119 (58.9\%) were from rural areas. Seroprevalence of H.pylori infection was found to be 79/202 (39.1\%, 95\% CI: 32.3 -45.7). As the age increased the risk of having H.pylori infection also increased (OR: 1.02 95\% CI: 1-1.04, $\mathrm{P}=0.02)$. On multivariate logistic regression analysis untreated drinking water was found to predict H.pylori seropositivity (OR: 2.33, CI: 1.09-4.96, $\mathrm{p}=0.028)$.

Conclusion: The seroprevalence of H.pylori among dyspeptic patients is high in this setting. Therefore the community in Mwanza should be educated on the use of safe drinking water in order to minimize $H$. pylori infections.

Keywords: H.pylori, dyspepsia, Tanzania.

DOI: http://dx.doi.org/10.4314/ahs.v16i3.7

Cite as: Jaka H, Mushi MF, Mirambo MM, Wilson L, Seni J, Mtebe M, Mshana SE. Sero-prevalence and associated factors of Helicobacter pylori infection among adult patients with dyspepsia attending the gastroenterology unit in a tertiary hospital in Mwanza, Tanzania. Afri Health Sci 2016;16(3): 684-689. DOI: http://dx.doi.org/10.4314/ahs.v16i3.7
\end{abstract}

\section{Background}

Helicobacter pylori is one of the major public health problems worldwide. More than half of the world's population is infected and humans are considered to be the only reservoirs ${ }^{1}$. H.pylori infections can lead to gastritis, peptic ulcer, gastric carcinoma and mucosal associated lymphoid tissue (MALT) lymphoma². Majority of the infected individuals are asymptomatic; nevertheless
Corresponding author:
Mariam M Mirambo,
Department of Microbiology/Immunology,
Weill Bugando School of Medicine,
P.O.Box, 1464, Mwanza, Tanzania
Email: mmmirambo@gmail.com

a small percentage tends to develop manifestations of peptic ulcer diseases later in life ${ }^{1}$.

H.pylori is commonly transmitted by fecal oral route through contaminated water and food ${ }^{3}$. Lack of proper sanitation, basic hygiene, poor diets and overcrowding have been found to play a significant role in H.pylori infection ${ }^{4}$. H.pylori infection is common throughout the world, the seroprevalence as high as $>90 \%$ has been reported in many developing countries compared to $1.2-48.8 \%$ in developed countries ${ }^{5}$. In Africa the seroprevalence has been found to range between $19.26 \%$ and $92 \%$, while in Tanzania the prevalence range from 65\%-79\% among dyspeptic patients ${ }^{7,8}$. A wide variation in the seroprevalence of H.pylori infection within and between different populations has been observed. Despite these variations 
there is no single study in Mwanza to show the magnitude of previous $H$. pylori infections. This study was done for the first time in Mwanza, Tanzania to investigate the magnitude and factors associated with previous H.pylori infection.

\section{Materials and methods Study design and settings}

This was a cross-sectional hospital based study conducted at gastroenterology unit at the Bugando Medical Centre (BMC) between June and July 2014 to investigate the magnitude of H.pylori infection. The study included all dyspeptic patients who consented to participate in the study. BMC is a tertiary, consultant and teaching hospital serving a population of about 13 million in the Lake zone of Tanzania.

\section{Sample size and sampling}

The sample size was determined by using Kish Leslie formula; a proportion of $22.5 \%$ was used ${ }^{9}$. The minimum sample size obtained was 188 . Dyspeptic adult patients with no active bleeding were serially enrolled until the sample size was reached.

\section{Data collection}

A standardized structured data collection tool was used to collect associated factors such as demographic and general characteristics. Dyspepsia was defined as difficult, or disturbed digestion, which may be accompanied by symptoms such as epigastric pain, nausea, vomiting, bloating and heartburn ${ }^{10}$. In this study illiterate and primary school level was defined as low education while secondary school and tertiary level were defined as high education. Treated drinking water was defined as water from the city supply or commercial available bottled water.

To determine H.pylori specific IgG antibodies about 4-5ml of blood sample was drawn from participants and placed in a plain vacutainer tubes (BD, UK). Specimens were taken to BMC laboratory where sera were extracted. H.pylori IgG antibodies were detected using rapid immunochromatographic kits (Flexsure-HP, SmithKline Diag- nostics, Inc USA). The test has specificity and sensitivity of $95 \%$ and $96 \%$ respectively ${ }^{11}$.

\section{Data analysis}

Data was entered in the computer using excel software and analysed using STATA version 11(STATA Corp LP, USA). The main outcome in this study was being H.pylori IgG antibody positive. Categorical variables such as sex, residence, source of drinking water, education level, water treatment, and hand washing before eating were summarized as proportions while age was summarized as median with interquartile range (IQR). Univariate and multivariate logistic regression analysis were done to determine factors predicting H.pylori infection. Factors with p- values less than 0.05 were considered statistically significant at $95 \%$ confidence interval (CI).

\section{Ethical considerations}

The study was approved by the joint CUHAS/BMC research ethics and review committee and permission was obtained from gastroenterology unit administration. Written informed consent was sought from each participant prior to enrolment in the study.

\section{Results}

\section{Demographic characteristics}

A total of 202 patients were recruited at the gastroenterology unit with median age of 42(IQR: 33-54) years. Females 105(51.9\%) formed majority of the study population. Of 202 participants; 119(59\%) and 83(41\%) were residing in rural and urban areas respectively. Regarding occupational status; 16(7.9\%) were students, $46(22.7 \%)$ were employed and 140(69.3\%) were unemployed.

\section{Prevalence and factors associated with H.pylori in- fections}

A total of $79(39.1 \%$; 95\% CI: 32.3 -45.7) participants were sero-positive for H.pylori. As the age increased the risk of having H.pylori infection also increased (OR: 1.02 95\% CI: 1-1.04, $\mathrm{P}=0.02$ ) (figure1). 
Figure 1: As the age increases the risk of having $H$. pylori infection also increases by $2 \%$ while the seroprevalence of $\boldsymbol{H}$.pylori increases by $0.5 \%$

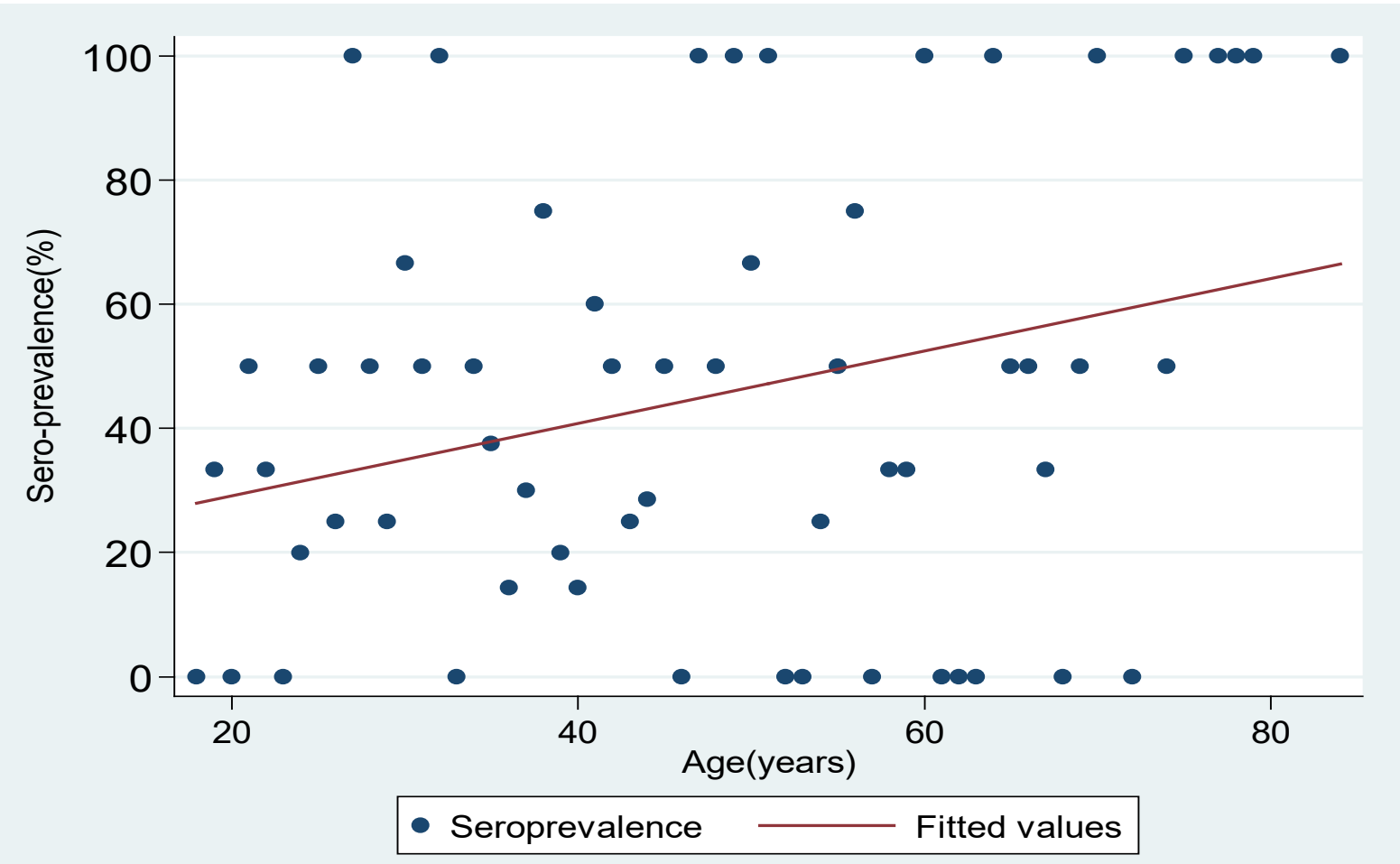

On univariate logistic regression analysis; low education level was significantly associated with H.pylori seropositivity (49.5\% vs. $28.7 \%$; OR: 2.43 , CI 1.36-4.35, $\mathrm{P}=0.003)$. Patients who used untreated drinking water had 2.33 times risk of getting $H$.pylori infection compared to those used treated water $(58.7 \%$ vs. $30 \%, \mathrm{P}<0.001)$ table1. Only water treatment was found to be an independent predictor of H.pylori seropositivity on multivariate logistic regression analysis (OR: 3.28, CI: 1.77-6.10, $\mathrm{P}=0.028$ ). (Table 1) 
Table1: Univariate and multivariate logistic regression analysis of factors associated with H.pylori infection among 202 adult patients

\begin{tabular}{|c|c|c|c|c|c|}
\hline \multirow[t]{2}{*}{ Characteristics } & \multirow{2}{*}{$\begin{array}{l}\text { Positive test (N, } \\
\%)\end{array}$} & \multicolumn{2}{|l|}{ Univariate } & \multicolumn{2}{|l|}{ Multivariate } \\
\hline & & OR(95\% Cl) & $P$ value & OR(95\% Cl) & $\begin{array}{l}P \\
\text { value }\end{array}$ \\
\hline Age(years) & 42(IQR:33-54) & $1.02(1-1.04)$ & 0.024 & $1.01(0.98-1.03)$ & 0.469 \\
\hline \multicolumn{6}{|l|}{ Sex } \\
\hline Male(97) & $36(37.11 \%)$ & 1 & & & \\
\hline Female (105) & $43(40.95 \%)$ & $1.17(0.66-2.07)$ & 0.577 & $1.31(0.69-2.44)$ & 0.410 \\
\hline \multicolumn{6}{|l|}{ Occupation } \\
\hline Students(16) & $4(25 \%)$ & 1 & & & \\
\hline Not employed(141) & $58(41.13 \%)$ & $2.09(0.64-6.82)$ & 0.219 & & \\
\hline Employed(45) & $17(37.78 \%)$ & $1.82(0.51-6.56)$ & 0.359 & $1.93(0.92-4.02)$ & 0.08 \\
\hline \multicolumn{6}{|l|}{ Education level } \\
\hline High (101) & $29(28.7 \%)$ & 1 & & & \\
\hline Low (101) & $50(49.5 \%)$ & $2.43(1.36-4.35)$ & 0.003 & $1.32(0.64-2.67)$ & 0.448 \\
\hline \multicolumn{6}{|l|}{$\begin{array}{l}\text { Source of drinking } \\
\text { water }\end{array}$} \\
\hline Tape water( 101) & $32(31.68 \%)$ & 1 & & & \\
\hline Other sources(101) & $47(46.53 \%)$ & $1.87(1.05-3.32)$ & 0.031 & $0.83(0.39-1.77)$ & 0.634 \\
\hline \multicolumn{6}{|l|}{ Water treatment } \\
\hline Yes(139) & $42(30.22 \%)$ & 1 & & & \\
\hline $\mathrm{No}(63)$ & $37(58.73 \%)$ & $3.28(1.77-6.10)$ & $<0.001$ & $2.33(1.09-4.96)$ & 0.028 \\
\hline \multicolumn{6}{|l|}{$\begin{array}{l}\text { Hand washing } \\
\text { before eating }\end{array}$} \\
\hline $\mathrm{No}(18)$ & $7(38.89 \%)$ & $1.02(0.37-2.7)$ & 0.984 & $1.11(0.37-3.30)$ & 0.854 \\
\hline \multicolumn{6}{|l|}{ Residence } \\
\hline Urban(83) & $27(32.5 \%)$ & 1 & & & \\
\hline Rural(119) & $52(43.70 \%)$ & $1.69(0.89-2.88)$ & 0.111 & $1.00(0.49-2.06)$ & 0.984 \\
\hline
\end{tabular}

\section{Discussion}

Although many individuals with $H$. pylori gastric colonization are asymptomatic, often those who seek medical attention may present with dyspepsia. Prolonged infection may result in gastric ulcers formation. The current study indicates the true magnitude of H.pylori infection among dyspeptic patients in our settings. Based on the natural history of the disease the seropositive individuals in the present study have $10-20 \%$ life time risk of developing peptic ulcers ${ }^{12}$ with $1-2 \%$ of the infected subjects at risk of developing gastric cancer ${ }^{13}$. This study has found comparable prevalence of H.pylori infection among dyspeptic patients as previously reported in Africa ${ }^{7,8,14,15}$. As compared to other studies in Africa ${ }^{6,16}$ the observed prevalence in the current study is lower and this could be explained by geographical variation as documented previously $^{17,18}$. Moreover; the sensitivity of the method used may explain such a difference.

However, this prevalence is higher as compared to previous reports from developed countries ${ }^{19-22}$. This could be explained by poor living conditions which favor H.pylori transmission in developing countries.

African Health Sciences Vol 16 Issue 3, September 2016 
In this study the odds of having H.pylori infection increased as the age increased which coincides with what has been reported earlier ${ }^{14,15,23}$ and contrary to data from Uganda where the prevalence was found to decrease as the age increased ${ }^{24}$. This could be explained by different study populations whereby in Uganda study the population studied was patients with different levels of malignancies. As suggested earlier gastric changes such as malignancies may cause decline of H.pylori specific antibodies and is likely to occur in patients with advanced disease and age; which is not the case in our study ${ }^{25}$.

On univariate logistic regression analysis, the odds of having H.pylori infections were significantly higher in rural areas compared to urban areas. Similarly, the odds of having H.pylori infection were higher among people with low education level than those with higher education level. Our findings are inconsistent with the previous studies which reported higher prevalence rates in urban areas and those with good socioeconomic status $^{26,27}$. In rural settings of Mwanza majority of population have low socioeconomic status whereby the main economic activities are small scale farming and fishing unlike in urban areas where majority of the urban population have high education level and good socioeconomic status.

In the present study, untreated drinking water was independently found to predict H.pylori infections. These findings are in agreement with what has been reported earlier ${ }^{3,4}$ whereby unsafe drinking water and poor hygiene were found to be associated with H.pylori infection. Moreover; low education level in almost half of these participants and majority being from rural areas may explain why they cannot afford to treat water despite the fact that it is unsafe to drink.

\section{Study limitations}

Due to limited resources, endoscopy was not done; this resulted in failure to diagnose active disease because urease/histopathological and breath tests were not done. In addition stool antigen tests and other differentials of dyspepsia were not established ${ }^{28}$.

\section{Conclusion and recommendations}

Drinking untreated water and increasing age have been found to be associated with $H$. pylori infection. More studies should focus on assessing incidence rates in relation to age. Improving drinking water in our setting will reduce H.pylori transmission and its associated complications such as gastritis, gastric ulcers and gastric malignancies. Moreover, community in Mwanza should be educated on the preventive measures as one of the efforts to control gastric diseases associated with H.pylori infection.

\section{Conflict of interest}

None declared

\section{Authors' contributions}

HJ, MMM, MM and SEM participated in the design of the work. HJ MFM and LW participated in the collection of specimens and clinical data. MMM, JS and LW performed serological tests. MMM, MM, JS and SEM analyzed and interpreted the data. MMM, MFM and SEM wrote the first draft of the manuscript. MMM and SEM critically revised the final draft of the manuscript. All authors read and approved the final version of the manuscript.

\section{Acknowledgements}

The authors would like to acknowledge the technical support provided by Mr.Vitus Silago. We thank all staff in gastroenterology unit at Bugando Medical Centre. This study was supported by research grant from CUHAS to HJ

\section{References}

1. Logan R, Gummett P, Schaufelberger H, Greaves R, Mendelson G, Walker M, Thomas P, Baron J, Misiewicz $\mathrm{J}$ : Eradication of Helicobacter pylori with clarithromycin and omeprazole. Gut 1994, 35:323-326.

2. Egan BJ, Holmes K, O’Connor HJ, O'Morain CA: Helicobacter pylori gastritis, the unifying concept for gastric diseases. Helicobacter 2007, 12:39-44.

3. Cave DR: Transmission and epidemiology of Helicobacter pylori. The American journal of medicine 1996, 100:12S-18S.

4. Hunt R, Xiao S, Megraud F, Leon-Barua R, Bazzoli F, Van der Merwe S, Vaz Coelho L, Fock M, Fedail S, Cohen $\mathrm{H}$ : Helicobacter pylori in developing countries. World Gastroenterology Organisation global guideline. J Gastrointestin Liver Dis 2011, 20:299-304.

5. Hazell S: H. pylori in developing countries. In Helicobacter pylori. Springer; 1994: 85-94

6. Asombang AW, Kelly P: Gastric cancer in Africa: what do we know about incidence and risk factors? Transac- 
tions of the Royal Society of Tropical Medicine and Hygiene 2012, 106:69-74.

7. Arun V, Mchembe M: Endoscopic Findings And Prevalence Of Helicobacter Pylori In Dyspeptic Patients Referred For Upper Gastrointestinal Endoscopy In Dar-EeSalaam. PMJUMU| PIONEER MEDICAL JOURNAL UMUAHIA 2012, 2.

8. Mbulaiteye SM, Hisada M, El-Omar EM: Helicobacter pylori associated global gastric cancer burden. Frontiers in bioscience: a journal and virtual library 2009, 14:1490.

9. Mujeere MP: Prevalence and factors associated with helicobacter pylori infection among children aged one month to twelve years in Mulago hospital. Makerere University, 2008.

10. Ford AC, Marwaha A, Lim A, Moayyedi P: Systematic review and meta-analysis of the prevalence of irritable bowel syndrome in individuals with dyspepsia. Clinical Gastroenterology and Hepatology 2010, 8:401-409.

11. Graham DY, Evans Jr DJ, Peacock J, Baker JT, Schrier WH: Comparison of rapid serological tests (FlexSure HP and QuickVue) with conventional ELISA for detection of Helicobacter pylori infection. American Journal of Gastroenterology 1996, 91.

12. Kusters JG, van Vliet AH, Kuipers EJ: Pathogenesis of Helicobacter pylori infection. Clinical microbiology reviews 2006, 19:449-490.

13. Correa P, Piazuelo MB: Natural history of Helicobacter pylori infection. Digestive and Liver Disease 2008, 40:490-496.

14. Mbulaiteye SM, Gold BD, Pfeiffer RM, Brubaker GR, Shao J, Biggar RJ, Hisada M: H. pylori- infection and antibody immune response in a rural Tanzanian population. Infect Agent Cancer 2006, 1.

15. Tanih N, Okeleye B, Ndip L, Clarke A, Naidoo N, Mkwetshana N, Green E, Ndip R: Helicobacter pylori prevalence in dyspeptic patients in the Eastern Cape province: race and disease status. SAMJ: South African Medical Journal 2010, 100:734-737.

16. Baako B, Darko R: Incidence of Helicobacter pylori infection in Ghanaian patients with dyspeptic symptoms referred for upper gastrointestinal endoscopy. West African Journal of Medicine 1995, 15:223-227.

17. Perez-Perez GI, Rothenbacher D, Brenner H: Epidemiology of Helicobacter pylori infection. Helicobacter 2004, 9:1-6.

18. Feldman RA, Eccersley AJP, Hardie JM: Epidemi- ology of Helicobacter pylori: acquisition, transmission, population prevalence and disease-to-infection ratio. British Medical Bulletin 1998, 54:39-53.

19. Chong V, Lim K, Rajendran N: Prevalence of active Helicobacter pylori infection among patients referred for endoscopy in Brunei Darussalam. Singapore Medical Journal 2008, 49:42-46.

20. Rahim AA, Lee YY, Majid NA, Choo KE, Raj SM, Derakhshan MH, Graham DY: Helicobacter pylori infection among Aborigines (the Orang Asli) in the northeastern region of Peninsular Malaysia. The American Journal of Tropical Medicine and Hygiene 2010, 83:1119-1122.

21. Roosendaal R, Kuipers EJ, Buitenwerf J, Van Uffelen C, Meuwissen S, Van Kamp GJ, Vandenbroucke-Grauls C: Helicobacter pylori and the birth cohort effect: evidence of a continuous decrease of infection rates in childhood. The American Journal of Gastroenterology 1997, 92:1480-1482.

22. Loffeld R, Van Der Putten A: Changes in prevalence of Helicobacter pylori infection in two groups of patients undergoing endoscopy and living in the same region in the Netherlands. Changes 2003, 38:938-941.

23. Bureš J, Kopáčová M, Koupil I, Voříšek V, Rejchrt S, Beránek M, Seifert B, Pozler O, Živný P, Douda T: Epidemiology of Helicobacter pylori infection in the Czech Republic. Helicobacter 2006, 11:56-65.

24. Newton R, Ziegler JL, Casabonne D, Carpenter L, Gold BD, Owens M, Beral V, Mbidde E, Parkin DM, Wabinga $\mathrm{H}$ : Helicobacter pylori and cancer among adults in Uganda. Infect Agent Cancer 2006, 1.

25. Forman D, Newell D, Fullerton F, Yarnell J, Stacey A, Wald N, Sitas F: Association between infection with Helicobacter pylori and risk of gastric cancer: evidence from a prospective investigation. British Medical Journal 1991, 6788:1302-1305.

26. Kawasaki M, Kawasaki T, Ogaki T, Kobayashi S, Yoshimizu Y, Aoyagi K, Takahashi S, Sharma S, Acharya GP: Seroprevalence of Helicobacter pylori infection in Nepal: low prevalence in an isolated rural village. European Journal of Gastroenterology \& Hepatology 1998, 10:47-50.

27. Torres J, Leal-Herrera Y, Perez-Perez G, Gomez A, Camorlinga-Ponce M, Cedillo-Rivera R, Tapia-Conyer R, Muñoz O: A community-based seroepidemiologic study of Helicobacter pylori infection in Mexico. Journal of Infectious Diseases 1998, 178:1089-1094.

28. Longstreth GF, Lacy BE, Talley NJ, Grover S: Approach to the adult with dyspepsia. UpToDate; 2013.

African Health Sciences Vol 16 Issue 3, September 2016 